\title{
Group Interaction and Behavior in Meetings: A New Assessment Tool to Monitor Group Behavior
}

\author{
Terry Oroszi \\ Pharmacology \& Toxicology Department, Boonshoft School of Medicine, Wright State University, \\ Fairborn, Ohio, USA \\ Email: terry.oroszi@wright.edu
}

How to cite this paper: Oroszi, T. (2020). Group Interaction and Behavior in Meetings: A New Assessment Tool to Monitor Group Behavior. Creative Education, 11, 596-604.

https://doi.org/10.4236/ce.2020.114044

Received: March 26, 2020

Accepted: April 25, 2020

Published: April 28, 2020

Copyright $\odot 2020$ by author(s) and Scientific Research Publishing Inc. This work is licensed under the Creative Commons Attribution International License (CC BY 4.0).

http://creativecommons.org/licenses/by/4.0/

\section{(c) (i) Open Access}

\begin{abstract}
Soft skills, such as verbal and nonverbal communication are important for success in business. Up to $80 \%$ of communication happens nonverbally, using standard and microforms of expression. Quantifying such skills can be difficult, so courses rarely prepare students for this much-needed skill (Henville, 2012). Organizational meetings are a hotspot for nonverbal communication. Demographics, such as rank and gender, may give meeting members the power to use negative nonverbal forms of communication to make themselves be heard or to show dislike of others. This is when it is particularly helpful to have a facilitator with skills in nonverbal communication to keep the group on task, following an agenda, and give empower the weak. The author created an assessment instrument with the help of anecdotal evidence and an exhaustive search of the current literature. The tool can be used to measure the behavior in the workplace and contributed to the creation of a classroom or workplace hands-on activity that will help students and employees hone their skills in identifying verbal, nonverbal, and microexpressions.
\end{abstract}

\section{Keywords}

Nonverbal Behavior, Communication, Social Interactions, Microexpressions, Facilitator, Communication Training

\section{Introduction}

Organizational meetings can be used to bring employees together to disseminate information, make decisions, and brainstorm ideas. Positive interaction can enhance the knowledge and effectiveness of the group; however, it is also possible 
that the interactions and displayed behavior will have a detrimental effect on the group's performance and ability to complete a task (Hackman \& Morris, 1974). The purpose of this paper is to introduce a new assessment tool that can be used to measure the behavior of the members and to offer a training tool that will help behaviors that can interfere with successful meetings. This requires an Assessment Instrument derived from anecdotal data and information from the current literature.

\section{Assessment Instrument}

The variables in this study measure identify verbal and non-verbal behavior patterns witnessed in meetings. The goal is to identify the patterns and look at how they are associated with the ethnicity, sex, and rank of the meeting participants, and use this as a tool to identify negative and positive contributors to a group.

The first group of variables is under the demographic category (see Figure 1). Ethnicity will be measured as white (1) or nonwhite (2). This is a dichotomous/nominal variable and with a frequency distribution one can determine percentages of each. Statistics used would be a Chi-square or Lambda. Along with one of the other variables, we can look for relationships and association respectively. The next variable is sex with male (1) and female (2). This is also a dichotomous/nominal variable and the same tests can be done as see with ethnicity. The rank variable is nominal. The rank variable will be defined by the rank of the members participating in the meeting, such as Dean-1/Chair-2/other-3 or CEO-1/Director-2/employee-3. Chi-square and logistic regression can be performed using Rank as a dependent variable (DV) and variables from the other categories operating as the independent variables (IV) independently (one IV and one DV). When used as the IV and the additional test, Cramer's V should be included if the variable picked is discrete, like rank. If the DV is continuous, it's best to perform a t-test, ANOVA, Regression and Correlation.

Under category "Attendance", there two variables of interest. Variable one is "Arrived late to the meeting". If a meeting member arrives after the meeting has started this response to this variable will be yes, if the member does not show up late this response is no. The next variable "Left the meeting early" is marked yes if a member leaves the meeting before the meeting has formally ended. In both

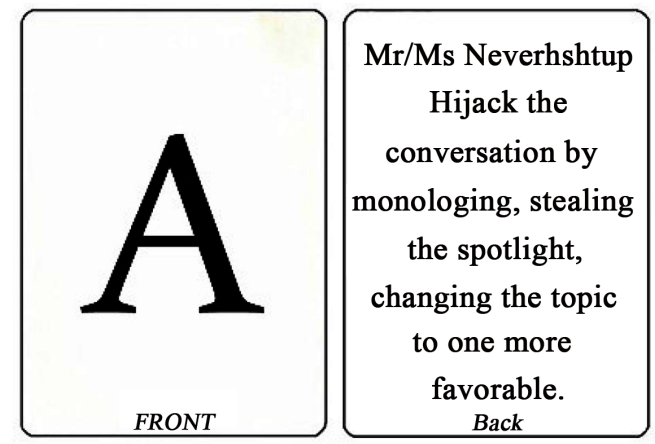

Figure 1. Card is placed on the table, letter up. 
cases, the time beyond the start and stop time is not indicated. This category is meant to indicate nonverbal communication and according to Neuman and Baron (1997) are examples of workplace aggression, in a physical, passive and indirect method.

The remaining categories and associated variables are all interval variables. Descriptive statistics, including frequency, should be performed on each of the variables independently. ANOVA and Measure of Association will be done when using any of the interval variables with the demographic (IV) variables.

The Verbal Interaction category covers, as the category states, verbal behaviors witnessed in meetings. This includes speaking at meetings and includes those that do not speak at meetings. One trend to look for in this category would be if a member attends ten meetings and never speaks, or speaks infrequently, is it because they are angry, do not feel they have a voice, or uninterested? This is where nonverbal communication skills can step in and identify the reason for lack of communication, and if a facilitator is present they can address the actions appropriately. Not speaking at a meeting can be due to several factors, this can be shyness, this can be sex-related, and women are known to speak less often in meetings (Umiker, 1990). Silence in a meeting can also be a form of passive-aggressiveness. This behavior is exhibited in a way that does not offend the other meeting members and reflects hostility but not in an open fashion (McIlduff \& Coghlan, 2000). Another variable in the Verbal Interaction category is the raising of the voice. Raising our voice is a way to generate power in meetings which makes it a good variable to include when studying member behavior at meetings (Umiker, 1990). How members handle being interrupted, talking louder, or not talking makeup two additional variables in this category. Lastly, and a commonly seen variable, is private conversations when someone else had the floor. The private conversations are often off-topic and these interruptions can degrade the effectiveness of the meetings (Yankelovich, McGinn, Wessler, Kaplan, Provino, \& Fox, 2005). Sidebar conversations are not always an attempt to disrupt a meeting. If a member feels confused about the topic, they may ask a person near them for clarification, in an attempt to not disrupt the meeting.

The Hijacking category includes five variables all to speaking in meetings. There have been several studies, like the one by Zimmerman and West (1996) that show us the tendency for males to interrupt a conversation. The interruption variable identifies when a speaker has his or her works or thoughts disturbed. It is important as a variable because it allows the interrupted speaker to gain control of the conversation and have their thoughts heard instead (Stratford, 1998). The other variables listed in the Hijacking category are variables witnessed in several types of meetings and may be considered appropriate because the user has never been called out on their bad behavior. Norms are often accepted if the behavior of the group members is predictable; this can include bad as well as good behavior (Feldman, 1984). The variable monologue is when a member answers a question but elaborates on the topic longer than necessary. Occasionally, this behavior is seen, not just excessively talking but changing the 
subject to something that is of interest to them in the process. Sometimes this is done even during a vote and can stall or prolong the voting process.

Personal Acts is the last category found in this observed behavior in the meeting assessment tool. They are acts done by an individual in a meeting that can be verbal or nonverbal and require only one member to do it. Some of the variables are positive; others will be seen as not positive acts. Crying is not common, but as Wasson (2000) pointed out the process of reaching consensus in a meeting can be quite emotional and may include conflict, crying, posturing and yelling. Showing positive behavior support in meetings was done with the final four variables. Touching another in to express positivity, performing an act of kindness, and offering support to another member in the meeting are all showing positive behavior support. The last variable, acting as a self-appointed facilitator is using the example of an informal leader taking charge when an appointed one may not be up to performing the task. The role of the facilitator is one of direction, not content-driven, but when meetings lose focus an informal facilitator may be needed to keep the meeting on track (Table 1).

\section{Nonverbal and Verbal Communication Training Tool}

To succeed leaders need soft skills, such as verbal and nonverbal communication (Bailey, 2018). Up to $80 \%$ of communication is done so by nonverbal speech (Pease, 2017). Like all skills, training if one is wanting to improve. Nonverbal communication, to include microexpressions, can be difficult to identify. The best method of communicating nonverbal expressions is through the face (Argyle, 1988), and the six most often accepted facial expressions are anger, disgust, fear, joy, sadness, and surprise (Argyle, 1988; Ekman, 2009; Kumar, 2010; Rane 2010).

A microexpression occurs when a person attempts to hide their emotions but cannot totally suppress an involuntarily express emotional facial expression (Zielke, Dufour, Hardee, Taylor, Jacobs, Blair, Buxkamper, Donahue, Keown, \& Trinh, 2011; Frank \& Svetieva, 2015). Microexpressions are extremely quick facial expressions of emotion that appear on the face. Individuals can be trained to better recognize these expressions and skills such as these can benefit law enforcement, medicine, security, and other professions that must read people (Frank \& Svetieva, 2015; Matsumoto \& Hwang, 2011; Hurley, 2012; Svetieva \& Frank, 2016).

Researchers agree that soft skills are important for success in business. Because soft skills are hard to quantify classes rarely prepare students for this much-needed skill (Henville, 2012). The assessment instrument helped create a tool that can be used to give students and employees the soft skills needed to improve their ability to understand and interpret nonverbal communication.

\section{Method}

This training is set up as a game. Games are an excellent way to teach content and enhance students' critical thinking abilities in college (Glendon \& Ulrich, 2005; Davis, 2019). 
Table 1. Observed behavior assessment instrument for meetings. The data collected to create this Assessment Instrument was approved by the Wright State University Institutional Review Board, SC\#5473.

\begin{tabular}{|c|c|}
\hline Variable and Categories (Unit of analysis - meetings) & Measure \\
\hline \multicolumn{2}{|l|}{ DEMOGRAPHICS (Independent Variables) } \\
\hline Ethnicity (white (1) or non-white (2)) & Dichotomous/Nominal \\
\hline Sex (male (1) or female (2)) & Dichotomous/Nominal \\
\hline Rank (High rank (1), Med rank (2), Low rank (3)) & Nominal \\
\hline \multicolumn{2}{|l|}{ ATTENDANCE $($ yes $=1$, no $=0$ ) } \\
\hline Arrived late to the meeting. & Dichotomous/Nominal \\
\hline Left the meeting early. & Dichotomous/Nominal \\
\hline \multicolumn{2}{|l|}{ VERBAL INTERACTIONS $($ no $=0$, once $=1$, twice $=2 \ldots)$} \\
\hline Spoke during the meeting. & Interval \\
\hline Raised his/her voice. & Interval \\
\hline Stopped talking when another interrupted. & Interval \\
\hline Became louder when someone attempted to interrupt. & Interval \\
\hline Spoke to the neighbor when someone else had the floor. & Interval \\
\hline \multicolumn{2}{|l|}{ HIJACKING $($ no $=0$, once $=1$, twice $=2 \ldots)$} \\
\hline Interrupted another speaking. & Interval \\
\hline Monologue (lengthy comments, $>1$ minute). & Interval \\
\hline Change the topic of conversation to their interests. & Interval \\
\hline Stalled a vote with one of the listed variables. & Interval \\
\hline \multicolumn{2}{|l|}{ PERSONAL ACTS (yes $=1$, no $=2$, more than once $=3$ ) } \\
\hline Used inappropriate gestures (loud sigh, extreme shaking of the head). & Interval \\
\hline Touched another member (to express anger or hostility). & Interval \\
\hline Was rude to another member. & Interval \\
\hline Threw an item in frustration. & Interval \\
\hline Cried & Interval \\
\hline Touched another member to express positivity. & Interval \\
\hline Act of Kindness (Gave up a seat, offered pen, paper). & Interval \\
\hline Offered support to another member at the meeting. & Interval \\
\hline Acted as a self-appointed facilitator & Interval \\
\hline
\end{tabular}

\section{Participants:}

- Chairperson

- Optional Facilitator

- Up to 16 Members (A - P)

- Up to 20 Watchers

Rules:

- Each Meeting Members receives a member card with their character name, 
keep the name and characteristics hidden. The letter is visible (see Figure 1). The members spend the meeting, acting out their character (subtle verbal and nonverbal attributes are spelled out on the back of each card). The names and their respective characteristics are posted somewhere that allows the watchers to view and compare.

- The Watchers receive a game card (see Figure 2) and use their knowledge to name the meeting members.

\begin{tabular}{|c|c|}
\hline Watcher Name & Total Correct \\
\hline Mr/Ms Nevershtup & A \\
\hline Manager Domb & B \\
\hline Asst. Director A. Noy & $\mathrm{C}$ \\
\hline Mr/Ms Vic. Tem & D \\
\hline $\mathrm{Mr} / \mathrm{Ms}$ Nonn Chalant & $\mathrm{E}$ \\
\hline Mr/Ms Frea' Spiret & $\mathrm{F}$ \\
\hline Mr/Ms E'go Maineact & G \\
\hline Mr/Mrs A. Pudding & $\mathrm{H}$ \\
\hline Vice President S. Climber & I \\
\hline Mr/Ms Rocket & $\mathrm{J}$ \\
\hline Mr/Ms Deadlee & $\mathrm{K}$ \\
\hline T. Dogge & $\mathrm{L}$ \\
\hline Mr/Ms Betafesh & M \\
\hline Director Dee Nigh & $\mathrm{N}$ \\
\hline Mr/Ms Toaduso & $\mathrm{o}$ \\
\hline Mr/Ms G. Giannt & $P$ \\
\hline
\end{tabular}

(a)

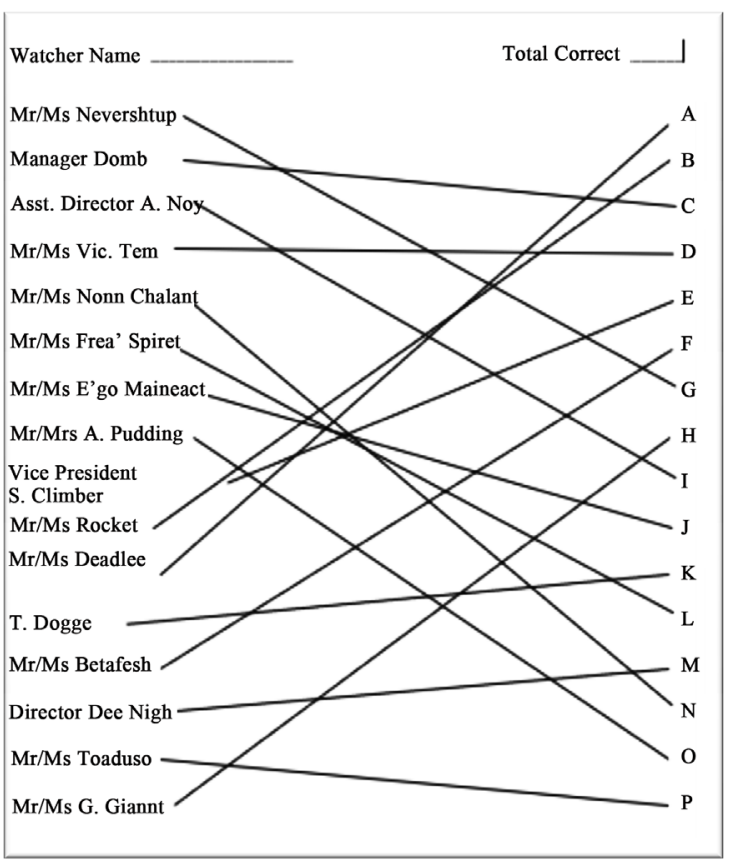

(b)

Figure 2. Watcher cards (a) Not used and (b) Characters linked to the letter on the cards. 


\section{Procedure}

- The Chairperson (and Facilitator) run the meeting using an agenda. Agenda topics are devised by the game organizers. The Watchers observe the meeting and watch the Memebers' verbal and nonverbal communication skills to determine their character. When the agenda has been accomplished the game is over, and the Watcher with the highest number of correct names wins. The Correct names indicate their success at interpreting verbal and nonverbal communication.

- The organizer may choose to include a facilitator to not Watchers. This can be done if there are a low number of players, or if this game is used as a training tool for facilitation. There can be more than one round. It is valuable to switch the Watchers and Members' roles and repeat the session. If the game continues with a second-round a new group of cards is needed, with the names changed (Table 2).

Table 2. Information found on the back of the member cards.

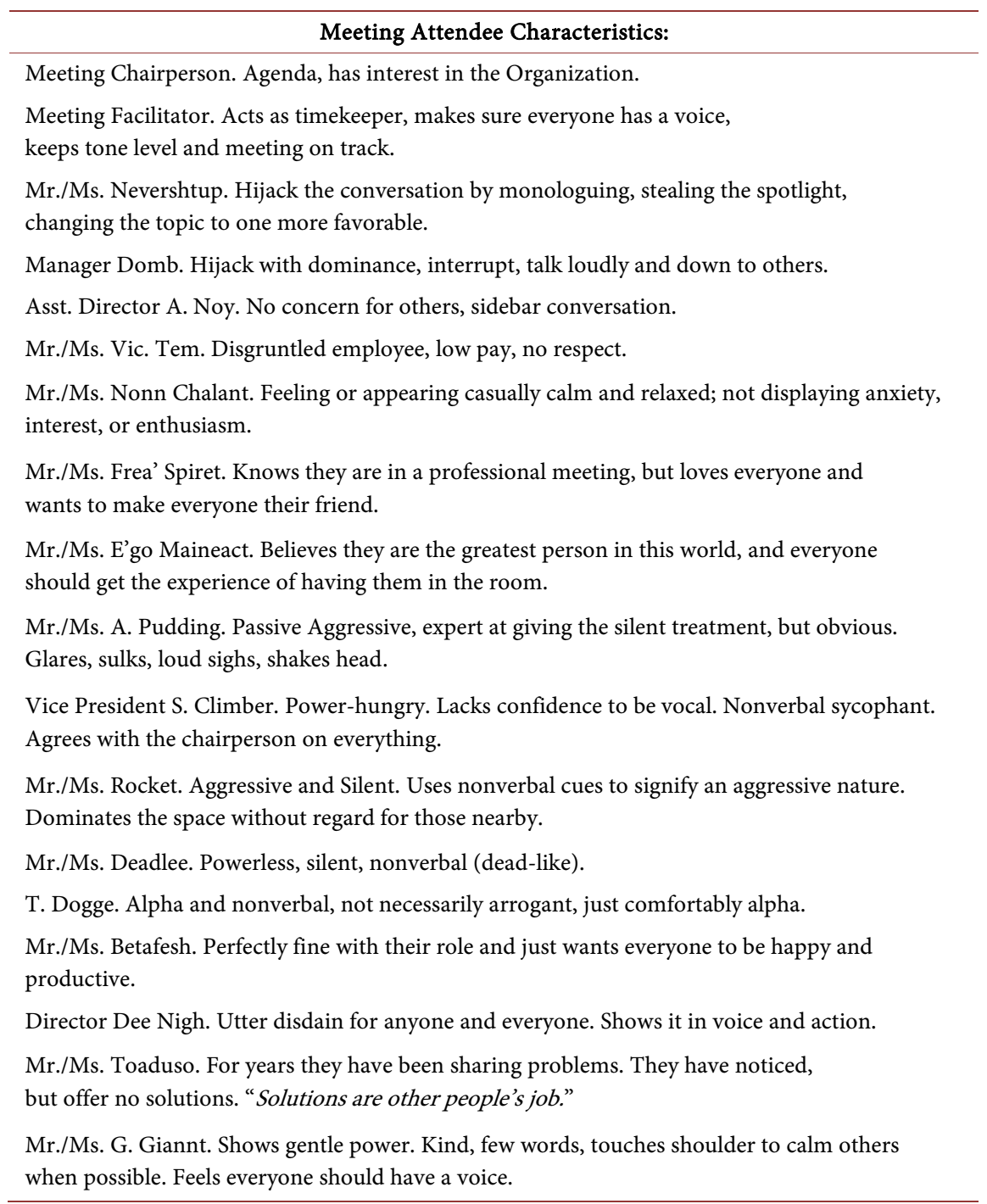




\section{Conclusion}

This paper set out to accomplish two aims. The first one was to offer an assessment instrument that can be used by facilitators, educators, or leaders, to determine bias in meetings in the form of verbal and nonverbal communication. Research shows that $60 \%$ to $80 \%$ of all communication is done nonverbally. Despite the need for this soft skill, it is hard to teach in the classroom. The second aim of this study was to provide a training tool in the form of a hands-on activity that can be used in the classroom or office to aid in recognizing nonverbal communication.

\section{Conflicts of Interest}

The author declares no conflicts of interest regarding the publication of this paper.

\section{References}

Argyle, M. (1988). Bodily Communication (2nd ed.). New York: Methuen.

Bailey, B. (2018). The Importance of Nonverbal Communication in Business and How Professors at the University of North Georgia Train Students on the Subject.

Davis, J. (2019). Teaching Strategies for the College Classroom. London: Routledge. https://doi.org/10.4324/9780429308260

Ekman, P. (2009). Telling Lies: Clues to Deceit in the Marketplace, Politics and Marriage. New York: W.W. Norton \& Co.

Feldman, D. C. (1984). The Development and Enforcement of Group Norms. Academy of Management Review, 9, 47-53. https://doi.org/10.5465/amr.1984.4277934

Frank, M. G., \& Svetieva, E. (2015). Microexpressions and Deception. In Understanding Facial Expressions in Communication (pp. 227-242). New Delhi: Springer. https://doi.org/10.1007/978-81-322-1934-7_11

Glendon, K., \& Ulrich, D. (2005). Using Games as a Teaching Strategy. Journal of Nursing Education, 44, 338. https://doi.org/10.3928/01484834-20050701-11

Hackman, J. R., \& Morris, C. G. (1974). Group Tasks, Group Interaction Process, and Group Performance Effectiveness: A Review and Proposed Integration. Defense Technical Information Center. https://doi.org/10.1016/S0065-2601(08)60248-8

Henville, N. (2012). Hard vs Soft Skills Training. Training Journal, 41-44.

Hurley, C. M. (2012). Do You See What I See? Learning to Detect Microexpressions of Emotion. Motivation and Emotion, 36, 371-381. https://doi.org/10.1007/s11031-011-9257-2

Kumar, R. (2010). Nonverbal Communication. In Basic Business Communication: Concepts, Applications and Skills (pp. 253-279). Excel Books.

Matsumoto, D., \& Hwang, H. S. (2011). Evidence for Training the Ability to Read Microexpressions of Emotion. Motivation and Emotion, 35, 181-191. https://doi.org/10.1007/s11031-011-9212-2

McIlduff, E., \& Coghlan, D. (2000). Understanding and Contending with Passive-Aggressive Behaviour in Teams and Organizations. Journal of Managerial Psychology, 15, 716-736. https://doi.org/10.1108/02683940010378072

Pease, A., \& Pease, B. (2017) The Definitive Book of Body Language. Harlequin.

Rane, D. B. (2010). Effective Body Language for Organizational Success. IUP Journal of 
Soft Skills, 4, 17-26.

Stratford, J. (1998). Women and Men in Conversation: A Consideration of Therapists' Interruptions in Therapeutic Discourse. Journal of Family Therapy, 20, 383-394. https://doi.org/10.1111/1467-6427.00094

Svetieva, E., \& Frank, M. G. (2016). Empathy, Emotion Dysregulation, and Enhanced Microexpression Recognition Ability. Motivation and Emotion, 40, 309-320.

https://doi.org/10.1007/s11031-015-9528-4

Umiker, W. (1990). How to Generate Power in Meetings. The Health Care Manager, 9, 33-38.

Yankelovich, N., McGinn, J., Wessler, M., Kaplan, J., Provino, J., \& Fox, H. (2005). Private Communications in Public Meetings. Paper Presented at the CHI'05 Extended Abstracts on Human Factors in Computing Systems, 1873-1876.

https://doi.org/10.1145/1056808.1057044

Zielke, M. A., Dufour, F., Hardee, G., Taylor, R., Jacobs, B., Blair, D., Buxkamper, A., Donahue, J., Keown, B., \& Trinh, D. (2011). Creating Micro-Expressions and Nuanced Nonverbal Communication in Synthetic Cultural Characters and Environments. In Proceedings of the Interservice/Industry Training, Simulation \& Education Conference (I/ITSEC).

Zimmermann, D. H., \& West, C. (1996). Sex Roles, Interruptions and Silences in Conversation. Amsterdam Studies in the Theory and History of Linguistic Science Series 4, 211-236. https://doi.org/10.1075/cilt.125.12zim 